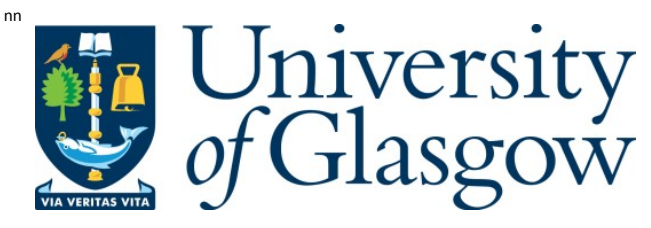

Ferguson, K., and Thomson, D. (2015) Performance comparison between a conventional helicopter and compound helicopter configurations. Proceedings of the Institution of M echanical Engineers, Part G : J ournal of Aerospace Engineering.

Copyright @ 2015 SA GE Publications.

A copy can be downloaded for personal non-commercial research or study, without prior permission or charge

Content must not be changed in any way or reproduced in any format or medium without the formal permission of the copyright holder(s)

http://eprints.gla.ac.uk/103623/

Deposited on: 04 M arch 2015

Enlighten - R esearch publications by members of the U niversity of Glasgow http://eprints.gla.ac.uk 


\title{
Performance Comparison between a Conventional Helicopter and Compound Helicopter Configurations*
}

\author{
Kevin Ferguson \\ k.ferguson.1@research.gla.ac.uk \\ Ph.D Student \\ University of Glasgow \\ Glasgow, United Kingdom
}

\author{
Douglas Thomson \\ Douglas.Thomson@glasgow.ac.uk \\ Senior Lecturer \\ University of Glasgow \\ Glasgow, United Kingdom
}

\begin{abstract}
The compound helicopter is a high speed design concept that is once again being explored due to emerging requirements for rotorcraft to obtain speeds that significantly surpass the conventional helicopter. This increase in speed, provided efficient hover capability is maintained, would make the compound helicopter suitable for various roles and missions in both military and civil markets. The aim of this paper is to investigate the compounding of the conventional helicopter and how the addition of thrust and wing compounding influences the performance of this aircraft class. The paper features two compound helicopters. The first configuration features a coaxial rotor with a pusher propeller providing additional axial thrust, and is referred to as the coaxial compound helicopter. The second configuration, known as the hybrid compound helicopter, features a wing and two propellers providing thrust compounding. In this study, the performance of these two compound helicopter configurations are assessed and compared with a conventional configuration. The paper presents the standard performance parameters of each configuration which include the power required in steady level flight, the maximum range, the maximum endurance and the hover ceiling of each of the aircraft configurations. Furthermore, a performance analysis of each configuration flying standard helicopter missions is conducted. The results of the hybrid configuration show that the addition of the wing to the design successfully offloads the main rotor at high speeds, however significant propulsive power is required by the propellers to overcome the airframe drag. Concerning the coaxial configuration, the power required by the coaxial compound and baseline configurations are comparable at low speeds. However, in high speed flight a significant amount of power is required by the propeller to divorce the coaxial rotor of its propulsive duties. The results also reinforce the importance of reducing airframe drag in a potential compound helicopter design.
\end{abstract}

*Manuscript accepted for publication in the Journal of Aerospace Engineering 


\section{Keywords}

Compound helicopter, Rotorcraft and performance.

\section{Nomenclature}

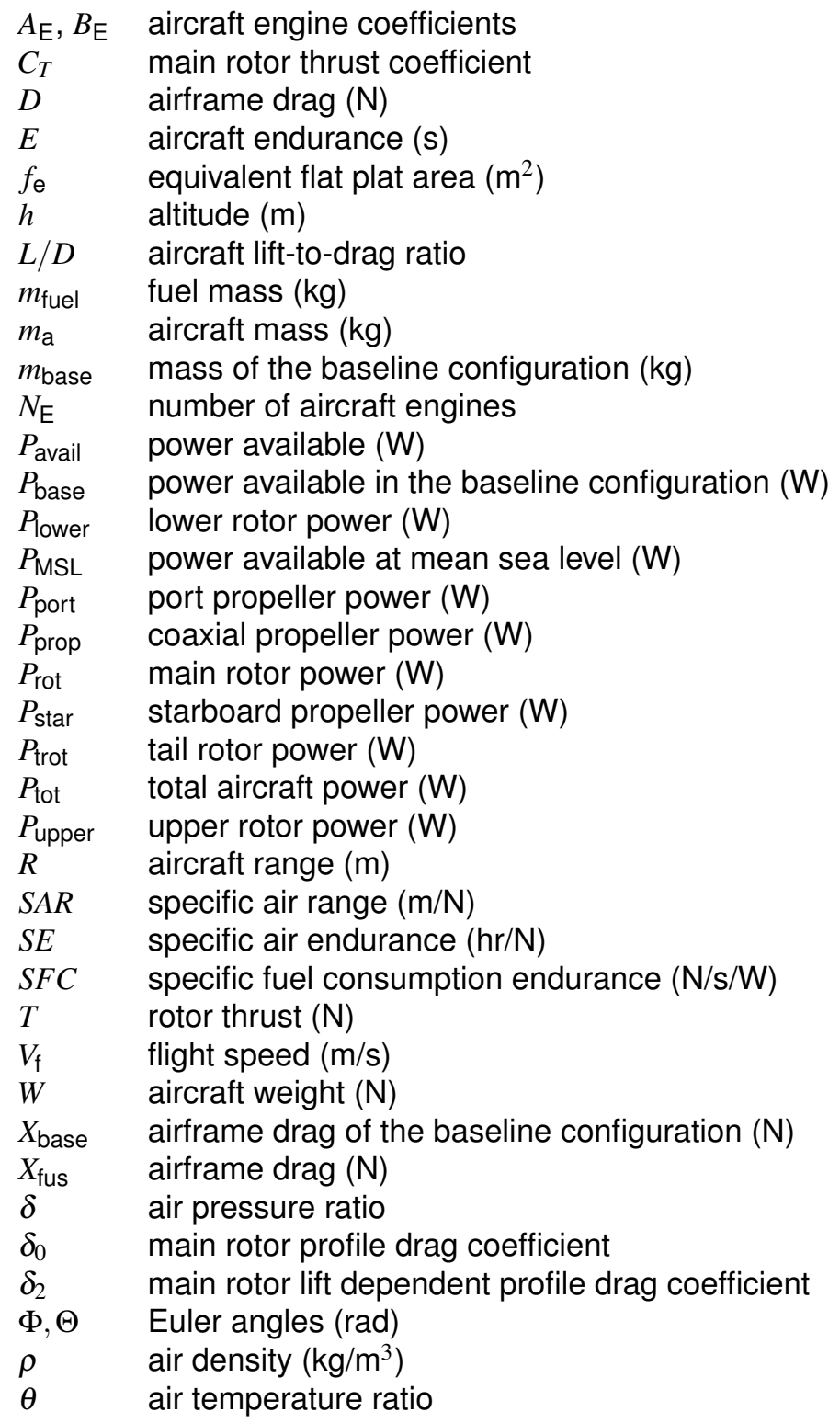

\section{Introduction}

The design of compound helicopter is again being explored as it can potentially satisfy the emerging requirements for the next generation of rotorcraft. The compound helicopter is a high speed design concept which aims to expand the flight envelope of the helicopter, therefore making it suitable for various roles such as ship replenishment and scouting missions. Although this is not a new concept, the development of a compound helicopter has proven elusive due to a combination of technical problems and economical issues [1]. Recently, various compound helicopter 
demonstrators have been developed, all of which are capable of reaching speeds that significantly surpass its conventional counterpart. For example, Sikorsky and Eurocopter, now Airbus Helicopters, are taking their compound helicopter demonstrators seriously with the flight tests of the Sikorsky X2 and the Eurocopter $X^{3}$ indicating promising results.

The main rotor of a conventional helicopter is responsible for providing the lifting and propulsive forces of the vehicle, which limits the maximum speed of a conventional helicopter due to aerodynamic limitations, installed engine power and airframe drag [2]. The problems associated with installed engine power and airframe drag can be minimised through careful design, but the main factor limiting the maximum speed of the helicopter is retreating blade stall. The compound helicopter is designed to delay the flight speed at which the condition of retreating blade stall occurs thereby increasing the maximum operating speed of the vehicle. Both the Sikorsky X2 and the Eurocopter $X^{3}$ have taken different approaches, to avoid this limit, in their respective compound helicopter prototypes. The X2, with its coaxial rotor, uses the ABC (Advancing Blade Concept) rotor system to offload the retreating side of the disc at high speeds and therefore avoid blade stalling. This concept was originally developed in the 1960s but the aircraft never entered production [3]. Recently, the ABC rotor system has been revisited and the design improved upon with the use of advanced aerofoil sections and active vibration control [4; 5]. Due to these improvements as well as the pusher propeller providing an extra component of axial thrust, the Sikorsky X2 is able to reach speeds of $250 \mathrm{kt}[6]$.

Due to the development of the Sikorsky X2 aircraft, there has been an increase of interest in the coaxial rotor arrangement with Johnson exploring the performance of the rotor system [7]. The comprehensive rotorcraft analysis (CAMRAD II) [8] package was used in this particular study to examine the performance of a coaxial rotor. With the vehicle weighing $150000 \mathrm{lb}$ and a coaxial rotor system optimised for cruise performance, the maximum lift-to-drag was calculated to be 6.2. Although Johnson estimates that this result may be somewhat optimistic, it does indicate that a coaxial compound helicopter could efficiently operate at $250 \mathrm{kt}$. Regarding another recent study of lift-offset rotors, Yeo and Johnson investigated the maximum blade loading of such a rotor system [9]. The results show that the thrust capability of the lift-offset rotor is significantly greater than that of the conventional rotor due to the system fully exploiting the lift potential of the advancing side of the rotor.

In a contrasting approach, the Eurocopter $X^{3}$ design features a conventional single main rotor with the addition of wings to the offload the rotor at high speeds with two propellers mounted onto the wing. In this approach, the propellers fulfil the dual purpose of providing the anti-torque moment and additional propulsive force. Recent publications have reported that the Eurocopter $X^{3}$ is able to reach a maximum speed of $232 \mathrm{kt}$. It is therefore evident that these helicopters are capable of greater speeds than their conventional counterparts.

In terms of a single main rotor compound helicopter, it is necessary to supplement it with a wing to offload the main rotor at high speeds. Furthermore, if the maximum speed is to be increased appreciably, then the design will also require auxiliary propulsion [10-13]. Yeo and Johnson, discuss the optimum design of a single main rotor 


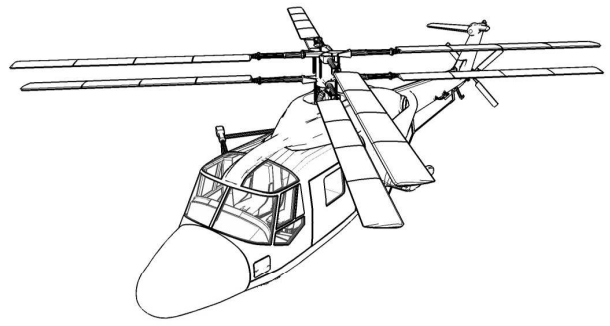

(a) Coaxial Compound Helicopter Sketch

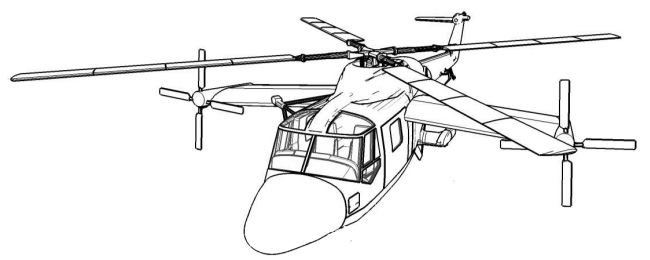

(b) Hybrid Compound Helicopter Sketch

\section{Fig. 1. Sketches of the two Compound Helicopter Configurations}

compound helicopter weighing 100,000lb [14]. The study concluded that the optimum performance occurred when the wing was producing the majority $(\approx 90 \%)$ of the vehicle lift and that the main rotor blade twist strongly influenced the aircraft performance. Another study by Moodie and Yeo, conceptually designed a slowed-rotor compound helicopter to achieve the best cruise performance [15]. The compound helicopter configuration within this study was similar in layout to that of the Lockhead Cheyenne, with the tail rotor and propeller mounted at the rear of the aircraft. The main rotor is slowed at high speeds, in order to avoid compressibility effects, with a billinear twist rate of $3^{\circ}$ inward and $-9^{\circ}$ outward selected to minimise power. The maximum take-off weight of the aircraft was calculated to be $36,851 \mathrm{lb}$, in order to carry a payload of $4015 \mathrm{lb}$, with the maximum lift-to-drag ratio at the cruise condition of 250 kt computed to be 7 . This result suggests that this particular configuration has a significant performance advantage when compared with a conventional helicopter. However, the authors are keen to stress that further work is required to assess how such a configuration would perform low speed manoeuvres as the large wing could present some challenges at this flight regime.

Clearly, there is no shortage of literature concerning the compound helicopter, which confirms the potential advantages of the vehicle. As the performance of the conventional helicopter is well understood [16], the next logical question relates to the performance of this aircraft class and how it compares to that of a conventional helicopter. The aim of this paper is to investigate the compounding of the conventional helicopter and how the addition of thrust and wing compounding influences the performance of this aircraft class. The authors are keen to stress that this work is not a design exercise, where the weights and power of each aircraft are sized to fulfil a required mission, but a study to determine the effects of compounding. Therefore, the results from this paper study should be viewed in this context. However, it is likely that the results from the study will highlight some design issues relating to the compound helicopter. With the aims of the paper determined, the strategy for the current work is to use an established mathematical model of a conventional helicopter (in this case the AgustaWestland Lynx), then convert this model to represent compound helicopter configurations. The Lynx was chosen as a well established data 
set [17] and model was available [18]. The fundamental design features and layout of the compound configurations that are examined in the paper are similar to the Sikorsky X2 and Eurocopter $X^{3}$. The first compound model is referred to as the Coaxial Compound Helicopter $(\mathrm{CCH})$ Model which features a coaxial rotor and a pusher propeller as seen in Figure 1(a). The second configuration is known as the Hybrid Compound Helicopter $(\mathrm{HCH})$ configuration which features a wing and two propellers, as seen in Figure 1(b). These two compound models are changed as little as possible, relative to the baseline configuration, to allow for a fair and direct comparison between the results of the compound configurations and the baseline $(\mathrm{BL})$ configuration. Therefore, unless stated, the design features of the compound helicopter configurations are identical to that of the conventional Lynx helicopter. There are only a few major design differences between the three aircraft configurations which include the introduction of thrust and wing compounding to the compound designs as well as the resizing of the main rotor of the $\mathrm{CCH}$ configuration to represent a rotor which is similar to the $\mathrm{XH}-59 \mathrm{~A}$ aircraft. The result is two rather unusual looking vehicles, Figures 1(a) and 1(b), however it should be recalled that this is not a design exercise, and so to ensure that the effects of compounding are isolated from other factors, the basic vehicle shape and size is maintained.

\section{Methodology}

This current study is a continuation of the compound helicopter work which focussed on the dynamic stability of these compound helicopter configurations [19]. The compound helicopter models are developed using the Helicopter Generic Simulation (HGS) model [17; 20]. The HGS model is a conventional disc-type rotorcraft model, as described by Padfield [17], a class of model which has found extensive use in studies of helicopter flight dynamics. The HGS model is generic in structure, with only the helicopter's parameters required to model the vehicle. The main rotor model, within the HGS package, ignores the lagging degree of freedom therefore assuming that the flap dynamics have the most influence in terms of the helicopter's flight dynamic characteristics. The flap dynamics are assumed to be quasi-steady, a common assumption in main rotor modelling, therefore permitting a multi-blade representation of the main rotor. The rotor model neglects the modelling of the rotor periodicity by assuming that only the steady components of the periodic forces and moments generated by the main rotor influence the helicopter's dynamics. The main rotor is centrally hinged with stiffness in flap with the main rotor chord assumed to be constant. Furthermore, the model also features a dynamic inflow model, an engine model and a rotorspeed governor model. One important assumption, within the rotor model, is that the aerodynamics are linear so that the lift is a linear function of the local blade angle of attack. Whereas the drag coefficient of each rotor blade section is modelled by the simple polynomial $C_{d}=\delta_{0}+\delta_{2} C_{T}^{2}$, where $\delta_{0}$ is the mean profile drag coefficient and the term $\delta_{2} C_{T}^{2}$ represents the drag due to blade incidence changes [21]. Due to this assumption, nonlinear aerodynamics such as retreating blade stall and compressibility effects are not modelled. To model nonlinear aerodynamics and rotor periodicity would require a high fidelity "individual blade model", some examples of which are given by various authors [22-26]. The fuselage model used within the study is taken from an established data-set of the AgustaWestland Lynx [17]. The fuselage and empennage data were determined from experimental wind tunnel results [17] and subsequently 
used in the rotorcraft simulations. Recall, that it is assumed that each of the three aircraft configurations have the same fuselage shape and size to isolate the effects of compounding. Thereby, allowing a fair and direct comparison between the three sets of results.

One question that naturally arises is the validity of these models and if the results from these rotorcraft models would replicate the real aircraft. In terms of the conventional helicopter, inverse simulation results have shown good correlation for a range of manoeuvres [27] giving confidence to the worth of the results produced by the HGS model. In relation to the compound helicopter models, a strict validation based on the comparison of flight test with simulation results is not possible as these are hypothetical vehicles. It should also be noted that the compound helicopter configurations can be trimmed for flight speeds that exceed $200 \mathrm{kt}$. However, in this study $200 \mathrm{kt}$ is assumed to be the helicopter's upper speed limit. At very high speeds it is important to model nonlinear aerodynamics [14], such as reverse flow, as a large portion of the local airflow across the retreating side of disc will travel from the trailing to the leading edge of the rotor blades. The current rotorcraft model does not model this nonlinear aerodynamic phenomenon and it is reasonable to expect that this limitation could produce unrealistic results at very high flight speeds. Hence, the performance analysis is restricted to speeds under $200 \mathrm{kt}$, where the modelling assumptions within the main rotor are still considered valid. Although compressibility effects are not modelled, the issue is attenuated by reducing the rotorspeeds of the main rotor systems of the two compound helicopters, above $130 \mathrm{kt}$. This reduction of rotorspeed is required as the local Mach number of advancing blade tip would approach unity, if uncorrected, leading to the formation of shock waves, thereby resulting in a significant increase of drag [28]. Therefore the current work does not assess the performance of the compound helicopters at the edge of their perceived flight envelopes. Although the compound helicopter is capable of reaching speeds in the region of $250 \mathrm{kt}$, it is still important to understand and quantify the performance of this aircraft class within the selected speed range where the aircraft will still spend a significant amount of time operating.

The approach taken with this study is to use the HGS package, with the limitations discussed previously, to quantify the performance of the three aircraft configurations. In terms of the sophistication of the main rotor modelling, Padfield conveniently splits the level of fidelity into three categories: level 1, level 2 and level 3 [17]. Level 1 represents a low fidelity approach to the main rotor modelling whereas level 3 describes high level rotor modelling [17]. There are comprehensive rotorcraft codes which have been developed which fall into Padfield's level 3 category [17], examples of which are the CAMRAD II [8] and NASA/US Army GENHEL codes [29], that use high level simulation techniques. These high fidelity rotorcraft simulations are predominately used in studies which focus on rotor design, vibration and the main rotor's stability [17]. In contrast, lower fidelity modelling techniques have found use in performance and flying qualities research [17]. Commonly, simple methods have been used to determine helicopter performance, with Stepniewski and Keys, Cooke and Fitzpatrick, Prouty, Leishman all providing analytical methods to quantify helicopter performance in their standard helicopter textbooks [2; 11; 30; 31]. These methods include momentum and blade element theories which can provide some good predications of rotorcraft 
performance. The modelling in this study is not as basic as many of the methods described in these textbooks but neither is it detailed as the modelling featured in some comprehensive rotorcraft codes. Hence, the modelling used in this work can perhaps be described as a reasonable compromise between these two extremes given the aims of the work. Comprehensive codes have been used in compound helicopter design studies [14; 15] where the aircraft was designed to operate at a speed in the region of $240 \mathrm{kt}$. It is clear that high level modelling is required in this flight regime where accurate modelling of yawed flow, reverse flow and compressibility effects become critical [32]. However, with the assumption that $200 \mathrm{kt}$ is the compound helicopter's boundary, it is fair to expect realistic results from the level of modelling used within this study. A similar level of modelling was used by Ormiston used in his compound rotorcraft study [33] to provide, as Ormiston states, a "fundamental understanding" of the performance of this aircraft class.

To assess the performance of the three aircraft configurations it is necessary to trim the vehicles. Concerning the $\mathrm{BL}$ configuration, the trim algorithm calculates the four control angles, roll and pitch angles which result in zero translational and angular accelerations acting at the aircraft's centre of gravity. In addition, the angular rates, sideslip velocity and glideslope angle are set to zero for all the trim calculations presented in this study. Essentially, there are six trim targets which are

$$
\begin{aligned}
X-m g \sin \Theta & =0 \\
Y+m g \cos \Theta \sin \Phi & =0 \\
Z+m g \cos \Theta \cos \Phi & =0 \\
L & =0 \\
M & =0 \\
N & =0
\end{aligned}
$$

which correspond to the condition of steady level flight. However, the introduction of extra control(s) to the compound helicopter configurations requires a slight amendment to the trim algorithm. In relation to the $\mathrm{HCH}$ configuration, there are five controls: the main rotor collective, two cyclic controls, a mean propeller pitch control and a differential propeller pitch control. The approach taken to determine the control angles required to trim this aircraft configuration is to prescribe an additional state which results in six unknowns which match the six trim targets, Equations (1) - (6). Presently, the extra state which is prescribed is the pitch attitude as it directly impacts the level of thrust that the propellers are required to produce. One possibility is to set a fixed value of pitch to trim the helicopter at all flight speeds; for example, $\Theta=0$ deg fuselage level. However, this is not always desirable, as it would require excessive levels of propeller thrusts at certain flight speeds. Another concern is that, in low-speed flight, there is no distinct advantage of having the propellers providing significant amounts of thrust, as it would unnecessarily increase the 
overall power consumption of the helicopter. Hence, rather than setting the pitch attitude to a fixed value for all flight speeds, a pitch schedule is developed. In low speed flight, the pitch schedule results in small amounts of propeller thrusts to provide the anti-torque moment. Whereas in speeds in excess of $150 \mathrm{kt}$, the pitch attitude is scheduled so that the wing's lift coefficient, $C_{L}$ is approximately 0.5 . This results in the wing providing a significant amount of lifting force whilst retaining an adequate stall margin.

The idea behind the $\mathrm{ABC}$ concept, featured in the $\mathrm{CCH}$ configuration, is that the lift potential on the advancing sides of the rotors discs is realised in high speed flight [34]. In this flight regime, the two rotors provide significant rolling moments around the rotor hub as the advancing sides of the discs produce much greater lift than the opposing retreating sides. However, the overall hub roll moment is zero as the upper and lower rotors provide rolling moments equal in magnitude but in opposing directions. This was achieved on the XH-59A aircraft by two methods. Firstly, by variable phase angle control which alters the azimuth position where the cyclic controls change the rotor blade pitch [34]. Secondly, by the introduction of a differential lateral cyclic control to promote greater loading across the advancing sides of the discs in high speed flight [34]. This study uses a differential lateral cyclic control on the aircraft to fulfil the lift potential of the advancing sides of the discs at high speeds. Hence, the $\mathrm{CCH}$ configuration features six controls: mean main rotor collective, differential main rotor control, two cyclic controls, propeller pitch and a differential lateral cyclic control. The approach taken to trim the $\mathrm{CCH}$ configuration is to prescribe an extra state, which is the pitch attitude, as well as introduce an additional trim target. The additional trim target is the lateral lift offset value, which is defined by Yeo and Johnson [9] as

$$
\operatorname{LOS}=\frac{\Delta M_{x}}{T R}
$$

where $\Delta M_{x}$ is the upper rotor rolling moment, $R$ is the rotor radius and $T$ is the total rotor thrust. The value of lateral lift offset, LOS is selected to vary with airspeed in the following manner

$$
L O S=A V_{f}^{2}
$$

so that no lateral offset is required in the hover but the value increases with speed. The lateral lift offset value is required to be within the range of $0.2-0.3$ to avoid retreating blade stall in high speed flight [35]. In this study the coefficient $A$ is selected so that the lateral lift offset value equals 0.2 at $200 \mathrm{kt}$ with all of the $\mathrm{CCH}$ configuration's results reflecting this. Therefore the trim algorithm calculates the seven unknowns to match the seven trim targets, which are Equations (1) - (7), so that the $\mathrm{CCH}$ configuration is in steady level flight. 


\section{Results}

\section{Power Required in Steady Level Flight}

The power required to operate an aircraft in steady level flight is important in any helicopter design. It is the goal of the designer to minimise the power required in steady level flight to maximise aircraft performance as well as provide an adequate power margin for the aircraft to perform manoeuvres. Figure 2 compares the predicted power of the $\mathrm{HCH}$ and $\mathrm{BL}$ configurations in steady level flight at mean sea level (MSL). Throughout the speed range the $\mathrm{HCH}$ configuration requires greater power when compared with the $\mathrm{BL}$ configuration. In the hover, the $\mathrm{HCH}$ configuration requires greater rotor power to overcome the aerodynamic download of the wing and the anti-torque moment is provided by the port and starboard propellers. The power of the tail rotor, in the hover, is $133 \mathrm{~kW}$ whereas the starboard and port propeller require $109 \mathrm{~kW}$ to retain the torque balance. Hence, the effect of thrust compounding is advantageous in this regard. As flight speed increases, a notch appears in the $\mathrm{HCH}$ configuration's rotor power at $50 \mathrm{kt}$ due to wing stalling. After a speed of $80 \mathrm{kt}$, combination of the wing offloading the main rotor and the main rotor slowing down to avoid adverse compressibility effects, reduces the main rotor power. However, this is met with an increase of power required by the two propellers, to overcome the fuselage drag and to maintain a near level pitch attitude to promote a favourable wing angle of attack. The net effect is that the power of the $\mathrm{HCH}$ configuration is greater than that of the $\mathrm{BL}$ configuration throughout the speed range. After $163 \mathrm{kt}$ the total power required exceeds the power available from the engine. This result, as expected, indicates that further optimisation of the design is required, particularly to reduce the airframe drag with technology such as active flow control [36]. The introduction of a low drag design would reduce the propulsive power required by the propellers and therefore lower the total power of the $\mathrm{HCH}$ configuration. Additionally, the results highlight that it may be necessary to increase the installed engine power of a hybrid compound helicopter relative to a conventional helicopter of similar mass. A similar conclusion was made during the investigation of the powerplant of a lift and thrust compounded Lynx demonstrator [37].

In relation to the $\mathrm{CCH}$ configuration, it has been a contentious issue whether or not a single main rotor design with a tail rotor is more efficient than a coaxial rotor design. To address this issue Kim and Brown [38; 39] used the vorticity transport model (VTM), which is a comprehensive rotor model, to compare the performance of a single rotor to that of a coaxial rotor. One important issue that Kim and Brown [38] highlight is that care must be taken when comparing a single rotor to that of a coaxial to ensure that a fair comparison can be made. Kim and Brown argue that to properly compare these two rotor systems the conventional single rotor must consist of an equal number of geometrically identical blades to those used in the coaxial rotor [38]. The reasoning for this approach is so that the differences between the two rotor systems are confined to the vertical separation of the rotors and not to the geometric differences of the rotor blades [38]. With this comparison method defined, Kim and Brown conclude that a coaxial rotor system consumes slightly less power than that of a single main rotor, a conclusion that is supported by Johnson [35]. Regarding the current modelling of the coaxial rotor, which is described in a flight 

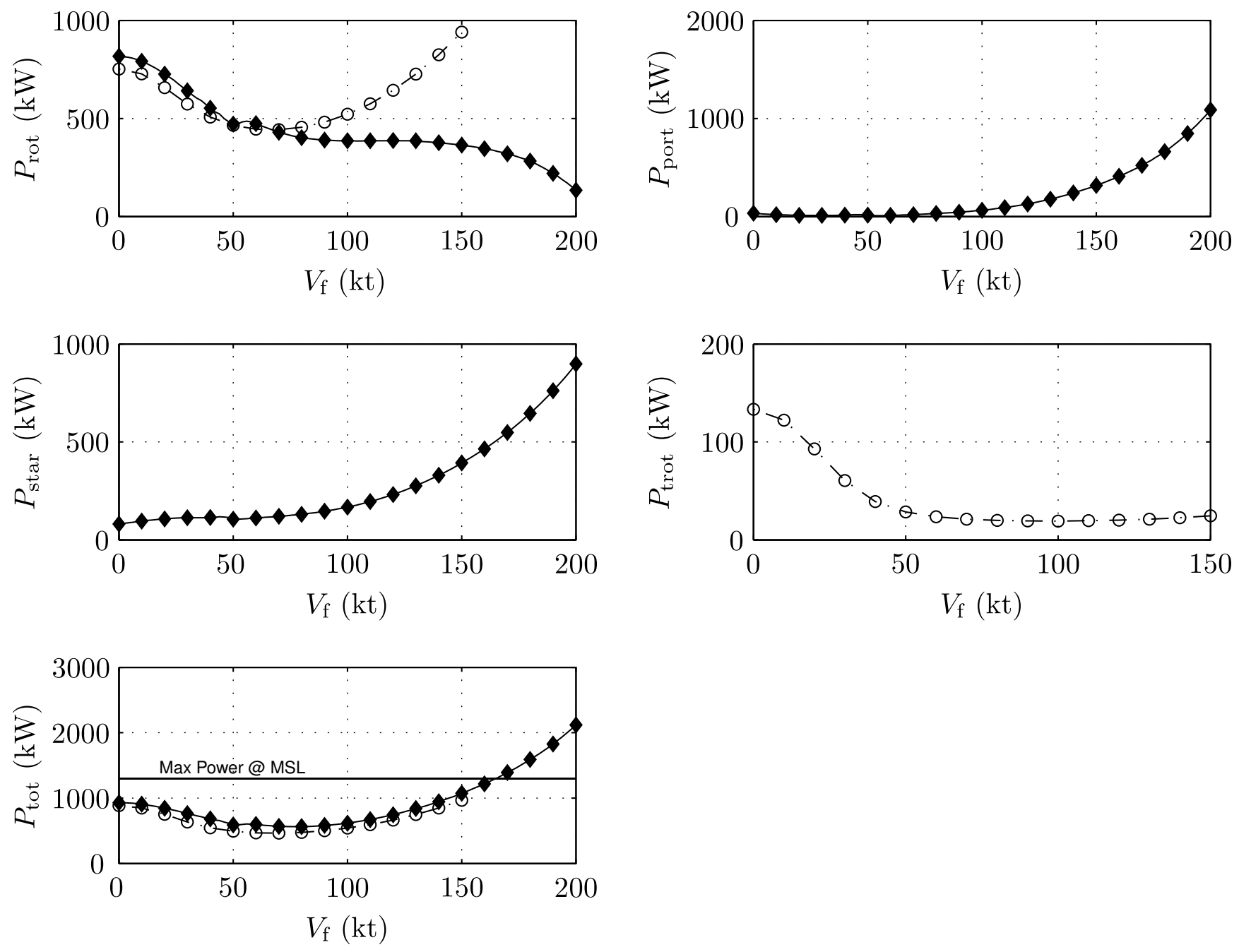

Fig. 2. Power Predicted for the $\mathrm{HCH}$ and BL Configurations in Steady Level Flight at MSL

dynamics investigation of compound helicopters by Ferguson and Thomson [19], the comparison of a coaxial rotor to that of a single rotor gives similar power predictions. This is perhaps due to the rudimentary nature of the coaxial inflow model which does not take into account the radial contraction of the upper rotor wake. However, the coaxial rotor model has shown to agree well [19] with the coaxial hover results provided by Harrington [40] and forward flight results by Dingeldein [41].

The power of the $\mathrm{CCH}$ and $\mathrm{BL}$ configurations are shown in Figure 3. The predicted main rotor hover power of the $\mathrm{BL}$ and $\mathrm{CCH}$ configurations are $765 \mathrm{~kW}$ and $922 \mathrm{~kW}$, respectively. The $\mathrm{CCH}$ configuration's rotor power is greater than that of the single rotor in the hover. This result is slightly misleading as it could be interpreted to suggest that the single main rotor is more efficient than the coaxial rotor. As mentioned in the previous discussion, to fairly compare the merits of the two rotor systems the single rotor must have the same amount of identical blades to that of its coaxial rotor counterpart [38]. The coaxial rotor has a solidity of 0.127 , which is based on the $\mathrm{XH}-$ 

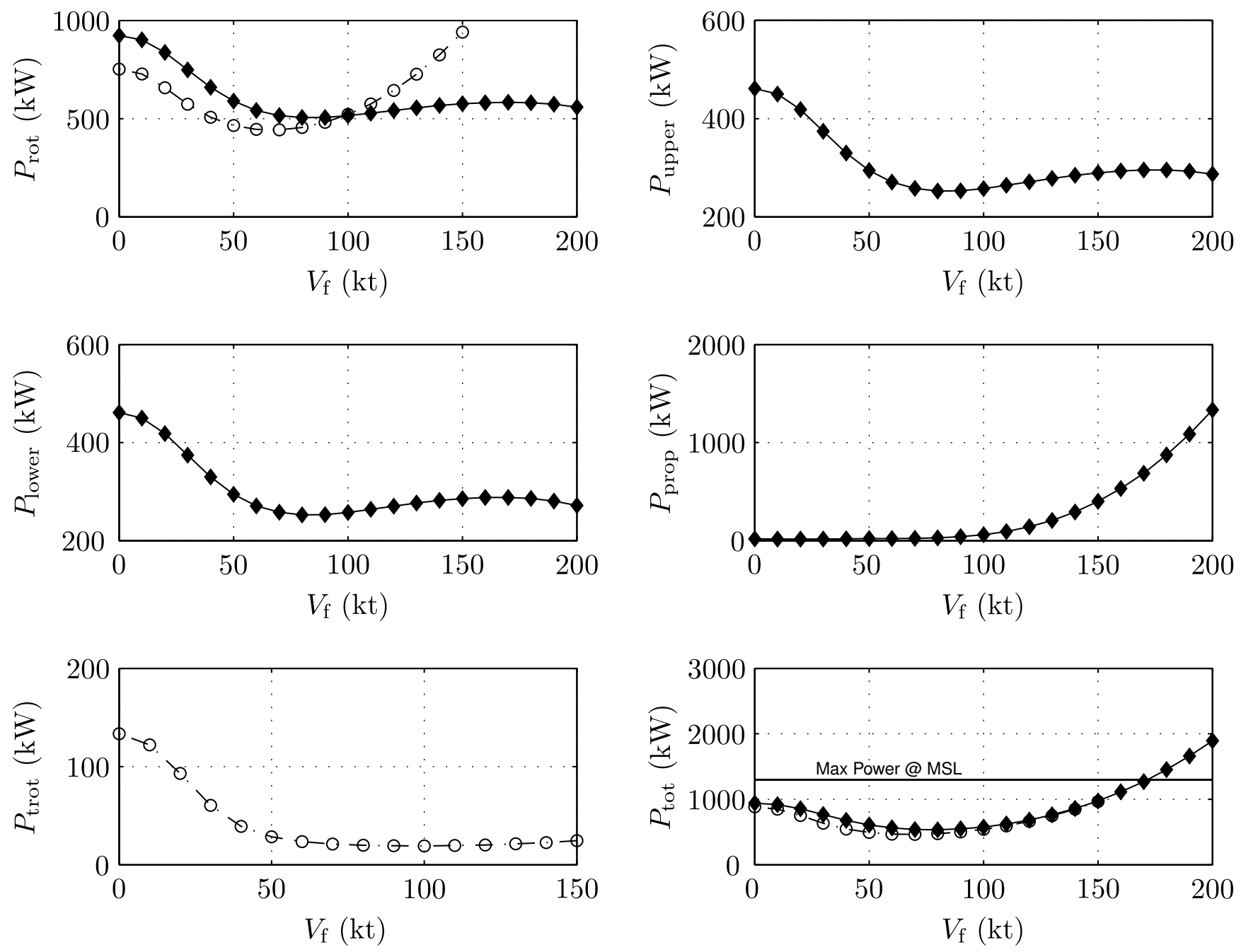

Fig. 3. Power Predicted for the $\mathrm{CCH}$ and BL Configurations in Steady Level Flight at MSL

59A demonstrator aircraft [42], whereas the conventional single rotor's solidity is 0.0777 . Hence, the coaxial rotor requires greater power in the hover due to its increased solidity which raises profile power losses. The high level of solidity featured on the XH-59A's main rotor was likely due to high speed design considerations. This design concept does not feature wing compounding, hence the coaxial rotor is responsible for providing the necessary lifting force at high speeds. The lateral lift offset fully exploits the high dynamic pressure on the advancing side of the rotor disc. However, on the opposite side of the rotor disc, the retreating side, a significant portion of the disc operates in reverse flow and therefore is incapable of contributing to the lifting force. This effectively reduces the rotor disc area and a high level of solidity is required to maintain the lifting force at high speeds. Returning to the presented results, the $\mathrm{CCH}$ configuration's rotor power reduces as it transitions into forward flight like that of the BL configuration. As the conventional helicopter moves into forward flight, the power begins to decrease reaching a minimum value at $68 \mathrm{kt}$. After this flight condition the power begins to rise due to the significant increase 

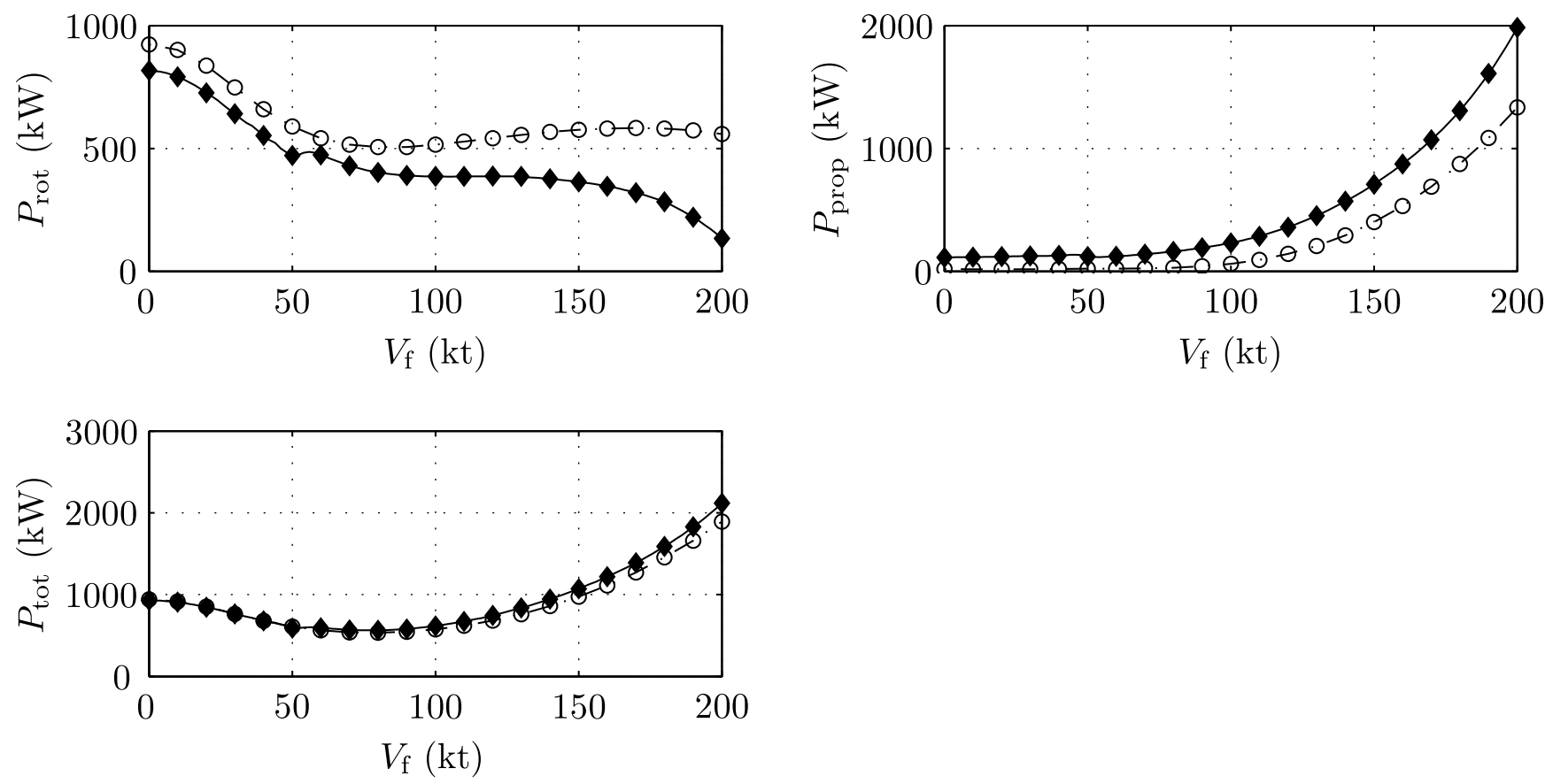

Fig. 4. Power Predicted for the $\mathrm{HCH}$ and $\mathrm{CCH}$ Configurations in Steady Level Flight at MSL

of airframe drag, requiring a large amount of propulsive power. This is generally one factor limiting the maximum speed of the helicopter as the power available is insufficient to overcome the airframe drag, which is proportional to $V_{\infty}^{3}$. In contrast, notice after $80 \mathrm{kt}$ that the coaxial rotor power does not increase significantly unlike the single main rotor. This is due to a combination of the propeller providing the propulsive power and the introduction of the lateral lift concept so that the lifting capability of the advancing sides of the coaxial rotor is realised. The total power of the $\mathrm{CCH}$ configuration is slightly greater than the $\mathrm{BL}$ configuration under $100 \mathrm{kt}$. After this flight speed the total power between the two configurations is comparable. The excess power of the $\mathrm{CCH}$ configuration becomes zero at approximately $160 \mathrm{kt}$ suggesting that for the aircraft to operate in this speed range requires an increase in installed engine power. Therefore the two compound helicopter configurations predict that a significant increase of installed engine power is required to operate these aircraft at a high speed range.

Figure 4 compares the predicted rotor, propeller and total power of the two compound configurations in steady level flight. Throughout the speed range, the $\mathrm{CCH}$ configuration requires greater rotor power. At high speeds the rotor of the $\mathrm{HCH}$ configuration is significantly offloaded by the wing whereas with the $\mathrm{CCH}$ configuration the rotor is required to provide the lifting force as well as a portion of the propulsive force. As the coaxial rotor system provides a portion of the propulsive thrust to overcome the airframe drag, the necessary propeller power is lower than that of the two propellers featured in the $\mathrm{HCH}$ configuration. 


\section{Maximum Speed}

As previously stated, the maximum speed of a conventional helicopter is restricted due to aerodynamic limitations, installed engine power and airframe drag [2]. Due to these restrictions, the maximum speed of a conventional helicopter may typically be limited to approximately $150 \mathrm{kt}$. However, the compound helicopter design aims to surpass this flight speed by the use of compounding to alleviate the aerodynamic limitations of the main rotor system. In this case the aircraft's speed may be limited by the installed power rather than retreating blade stall. Hence, for this analysis, it is assumed that the only restriction to the forward speed of the compound helicopter is the installed engine power. By making this assumption, the maximum speed of each compound configuration is determined by a Newton-Raphson technique which calculates the flight speed whereby the power available matches the power required by the vehicle.

Although the $\mathrm{HCH}$ and $\mathrm{CCH}$ configurations design parameters were determined in the development of the respective configurations [19], certain design parameters can be changed in order to observe their influence regarding aircraft performance. The design parameters which are of most interest are the installed engine power, mass and airframe drag of the configurations. It has been previously predicted that the compound configurations would need an increase of installed engine power relative to the BL configuration which would inevitably increase the mass of the vehicle. Therefore the affect of increasing the aircraft mass is of interest. Also, one of the main perceived advantages of the compound helicopter is that it has the ability to operate at high speeds where airframe drag becomes excessive. A conventional helicopter's fuselage is not as aerodynamically clean when compared to a fixed wing aircraft [21], therefore incurring a high drag penalty at high speeds. There are various sources of airframe drag which include the main rotor hub attachment, installation of the engine as well as the basic fuselage shape [43]. Hence, it seems likely that a successful compound helicopter design would feature a low drag rotor hub and fuselage design. There is a practical limit to which the fuselage drag could be reduced since the fuselage is required to hold the payload for various missions. Generally, the airframe drag is modelled by the equivalent flat plate drag area which represents both the fuselage and rotor hub drag. Therefore, the airframe drag is given by the simple relationship

$$
D=\frac{1}{2} \rho V^{2} f_{e}
$$

For the present study, the same fuselage shape and size is assumed for all of the three aircraft configurations, with its equivalent flat plate area approximately equal to $1.9 \mathrm{~m}^{2}$. However, due to drag reduction techniques, statistical data discussed by Ormiston [33], suggests that the equivalent flat plate area of a a low airframe drag design can be approximated with

$$
f_{e}=2.5\left(\frac{W}{1000}\right)^{2 / 3}
$$


Using this relationship and the current aircraft weight suggests that the airframe drag could be reduced by $25 \%$. This low drag fuselage design can be modelled simply by multiplying the original airframe drag force, $X_{\text {fus }}$, by 0.75 . Table 1 gives an overview of the design cases studied. The design parameters of Case E reflect, in all probability, what a compound helicopter would feature. An increase of engine power to operate the aircraft at a high speed range with a low drag airframe design. Also the mass is increased by a factor of 1.1 to compensate for additional installed power and the inclusion of propellers to the original design.

\begin{tabular}{lllll}
\hline \hline Case A & Case B & Case C & Case D & Case E \\
\hline$\cdot$ Standard Case & $\bullet P_{\text {avail }}=1.4 P_{\text {base }}$ & $\bullet X_{\text {base }}=0.75 X_{\text {fus }}$ & $\bullet M_{\mathrm{a}}=1.1 M_{\text {base }}$ & $\bullet P_{\text {avail }}=1.4 P_{\text {base }}$ \\
& & & $\cdot X_{\text {base }}=0.75 X_{\text {fus }}$ \\
& & & $\cdot M_{\text {a }}=1.1 M_{\text {base }}$ \\
\hline \hline
\end{tabular}

Table 1. Compound Helicopter Design Cases

The maximum speeds of the two compound helicopter configurations and design cases are shown in Table 2. Restricting the analysis to the $\mathrm{HCH}$ configuration, the maximum speed of case $\mathrm{A}$ is $163 \mathrm{kt}$ which is a modest increase relative to the $140 \mathrm{kt}$ maximum speed of the $\mathrm{BL}$ configuration [44]. Although the wing offloads the main rotor, the power of the two propellers increases to provide the propulsive power and to remain a near level fuselage attitude. Consequently, the maximum speed of the $\mathrm{HCH}$ configuration, case $\mathrm{A}$, is only slightly greater than that of the $\mathrm{BL}$ configuration. With the greater installed engine power, case B, there is an increase of maximum speed to $188 \mathrm{kt}$ which is a $25 \mathrm{kt}$ increase relative to case $A$. The reduction of fuselage drag, case $C$, increases the maximum speed by $15 \mathrm{kt}$. With case $\mathrm{D}$, the increased mass case, the maximum speed is lowered as the rotor power is increased to compensate for the additional weight of the vehicle. The greatest maximum speed is achieved by case $E$ due to the combination of the increase of engine power and the reduction of airframe drag.

In terms of the $\mathrm{CCH}$ configuration, for case A the maximum speed is $172 \mathrm{kt}$ which is greater than its $\mathrm{HCH}$ configuration counterpart. This result is consistent with Figure 4, which indicates that at flight speeds in the region of $160 \mathrm{kt}$ that the $\mathrm{CCH}$ configuration's power setting is lower than the $\mathrm{HCH}$ configuration. This consequently allows the $\mathrm{CCH}$ configuration to achieve a greater maximum speed. The cases of the $\mathrm{CCH}$ configuration exhibit a similar trend to the $\mathrm{HCH}$ configuration with the maximum speeds of cases $\mathrm{B}, \mathrm{C}$ and $\mathrm{E}$ rising when compared to case $\mathrm{A}$. Case $\mathrm{E}$ achieves the greatest speed of $216 \mathrm{kt}$ which is significantly higher than the maximum speed of the $\mathrm{HCH}$ configuration, suggesting that the $\mathrm{CCH}$ configuration is more suitable as a high speed design concept. Although, it is important to recall that the current rotor model assumes linear aerodynamics. Hence, the reverse flow region is not modelled and due to the high loading of the coaxial rotor at these high speeds a higher level of modelling would

\begin{tabular}{llllll}
\hline \hline \multirow{2}{*}{ Configuration } & \multicolumn{6}{c}{ Maximum Speed $(\mathrm{kt})$} \\
& Case A & Case B & Case C & Case D & Case E \\
\hline $\mathrm{HCH}$ & 163 & 188 & 178 & 161 & 202 \\
$\mathrm{CCH}$ & 172 & 197 & 189 & 170 & 216 \\
\hline \hline
\end{tabular}

Table 2. Maximum Speeds of the Compound Helicopter Cases 
be required to validate this result.

\section{Hover Ceilings}

The high speed aspect of the compound helicopter design is an attractive performance benefit, however the ability to efficiently hover is also key if the vehicle is to fulfil various missions and roles. One performance metric to indicate the hover efficiency of the helicopter is the hover ceiling. In order to predict the hover ceilings of these three aircraft configurations, each configuration is trimmed in the hover and their altitude varied until the power required matches the power available, within some given tolerance. The hover ceilings are estimated by the use of a simple NewtonRaphson numerical technique, to ensure rapid convergence. For the following analysis it is assumed that the power available, as described by Keys [45], is given by

$$
P_{\text {avail }} \approx P_{\mathrm{MSL}} \frac{\delta}{\theta}
$$

where, $\delta$ is the pressure ratio, given by the standard International Standard Atmosphere (ISA), as

$$
\delta=\left(1-2.2558 \times 10^{-5} h\right)^{5.265}
$$

The temperature ratio, $\theta$, and the temperature, in the units of ${ }^{\circ} \mathrm{C}$, can be calculated by

$$
T=15-0.001981 h
$$

Similar to that of the maximum speed analysis, design parameters are altered to investigate their effect on the hover ceilings, with only cases $A$ and $D$ being considered. The power available can be increased like that of cases $B$ and $E$, however is it found that with this high level of power available the helicopter configurations reach an altitude whereby the collective angles of the two main systems are excessive and therefore approaching stall. Since the modelling does not take into account nonlinear aerodynamics it is reasonable to expect the results from these particular cases to be unreliable, hence the results of these cases are not presented. Of course, case $C$ is also not studied as there is no parasitic drag arising from the fuselage in the hover.

The hover ceilings of the three aircraft configurations are shown in Table 3. As the BL configuration features the lowest power setting of each of the aircraft configurations in the hover, see Figures 2 and 3, it achieves the greatest hover ceiling of $3210 \mathrm{~m}$. Considering the $\mathrm{HCH}$ configuration, the hover ceiling is less than that of the BL configuration primarily due to the aerodynamic download of the wing which increases the rotor power to compensate. Although the wing is beneficial at high speeds to offload the main rotor, in hover and low speed flight it provides a significant download reducing low speed performance. This problem of aerodynamic download was encountered 


\begin{tabular}{llll}
\hline \hline & \multicolumn{3}{c}{ Hover Ceilings $(\mathrm{m})$} \\
Configuration & Case A & Case D & Case F \\
\hline $\mathrm{BL}$ & 3210 & 2280 & \\
$\mathrm{HCH}$ & 2786 & 1849 & 3143 \\
$\mathrm{CCH}$ & 2529 & 1583 & \\
\hline \hline
\end{tabular}

\section{Table 3. Hover Ceilings of Compound Helicopter Cases A, D and F}

in the development of the tilt-rotor and the use of flaps was shown the ameliorate the wing download in low speed flight [46]. It is likely that a winged compound helicopter would also implement the use of flaps although the weight penalty of the wing would also have to be considered. Therefore, case F represents the case where the wetted area of the wing is reduced by $60 \%$ by the use of flaps. The wing still provides an aerodynamic download, an inevitable consequence of lift compounding, but the power of the two propellers, to provide the anti-torque moment, is smaller than that of the conventional helicopter's tail rotor. The net effect is that the use of flaps results in comparable hover ceilings.

The $\mathrm{CCH}$ configuration achieves the lowest hover ceiling of the three aircraft configurations of $2529 \mathrm{~m}$. The effect of thrust compounding does not influence this result as the propeller only requires small levels of power in the hover. It should be stressed that this coaxial rotor system is not an optimum system such as that on the Sikorsky X2 which features nonlinear twist of the rotor blades. In order to minimise the induced power losses from the coaxial rotor system the twist of the lower rotor blade is required to be of double hyperbolic form, as shown by Leishman and Ananthan [47]. This is due to the radial contraction of the upper rotor's wake upon passing through the lower rotor. The rudimentary nature of this coaxial rotor inflow model used within this current study assumes no radial contraction of the upper rotor's wake and therefore is unsuitable to predict the performance benefit that nonlinear twist throughout the lower rotor blades offers. However, the coaxial rotor inflow model has been validated in previous compound helicopter work [19]. Perhaps a higher level of modelling and optimisation of the coaxial rotor system would predict reduced levels of power than the results presented.

\section{Range and Endurance}

The range and endurance of a helicopter indicate the capability of the aircraft to perform various missions and roles. There are various methods to predict these performance metrics but the approach presented in the following is given by Johnson [48]. Firstly, focusing on range, the range of a helicopter can be found by integrating the specific range over the total fuel weight, which is mathematically stated as

$$
R=\int_{0}^{m_{\text {fuel }}} \frac{d R}{d m_{\text {fuel }}} d m_{\text {fuel }}
$$

The specific air range, $d R / d m_{\text {fuel }}(\mathrm{SAR})$, is given by the following 


$$
\frac{d R}{d m_{\text {fuel }}}=\frac{1}{S F C} \frac{V_{\mathrm{f}}}{P_{\text {tot }}}
$$

where $S F C$ is the specific fuel consumption and $V_{\mathrm{f}} / P_{\text {tot }}$ is the optimum speed to power ratio to maximise range. The specific fuel consumption is a function of fuel flow rate and the power required, hence

$$
S F C=\frac{\dot{m}_{\text {fuel }}}{P_{\text {tot }}}
$$

In order to determine the specific fuel consumption, the fuel flow rate through the engine is required. The relationship between the fuel flow rate and power can be approximated with

$$
\frac{\dot{m}_{\text {fuel }}}{\delta \sqrt{\theta}}=N_{E} A_{E}+B_{E} \frac{P_{\text {tot }}}{1000 \delta \sqrt{\theta}}
$$

where $N_{E}$ is the number of engines and both $A_{E}$ and $B_{E}$ define the engines fuel flow with their units being $\mathrm{kh} / \mathrm{hr}$ and $(\mathrm{kg} / \mathrm{hr}) / \mathrm{W}$, respectively. Using data relating to the conventional aircraft's engine [49], the value of $A_{E}$ is approximated to be 30.61 , whereas $B_{E}$ is estimated to be 0.2067 . To determine the range of these aircraft the mass of fuel must be known. Since these are fictitious configurations it seems convenient to express the predicted range results in specific range form, so that the range can be determined by the product of the SAR and fuel mass. For the current analysis it is assumed that the specific fuel consumption and $V_{\mathrm{f}} / P_{\text {tot }}$ are independent of the vehicle weight. Furthermore, it is assumed that the ratio $V_{\mathrm{f}} / P_{\text {tot }}$ does not change over time, although in reality the optimum ratio of speed to power would be a function of altitude and vehicle weight. With these assumptions the SAR for the three aircraft configurations is shown in Figure 5(a). As expected, the BL configuration achieves the greatest specific air range of $114 \mathrm{~m} / \mathrm{N}$ at a speed of approximately $120 \mathrm{kt}$. The maximum SAR of the $\mathrm{CCH}$ configuration is slightly less than that of the $\mathrm{BL}$ configuration which is achieved at $130 \mathrm{kt}$. The results estimate that $\mathrm{HCH}$ configuration achieves the lowest SAR of $104 \mathrm{~m} / \mathrm{N}$ however an inherent advantage of a winged helicopter is the opportunity of carrying more fuel which would be factored into the design process.

As the helicopter is commonly used for search and rescue missions, the endurance of the aircraft is particularly important to maximise search time. The endurance of an aircraft is given by

$$
E=\int_{0}^{m_{\text {fuel }}} \frac{d E}{d m_{\text {fuel }}} d m_{\text {fuel }}
$$

where the specific endurance, $d E / d m_{\text {fuel }}(\mathrm{SE})$, is

$$
\frac{d E}{d m_{\text {fuel }}}=\frac{1}{\dot{m}_{\text {fuel }}}
$$

Figure 5 (b) shows the predicted specific endurance of the $\mathrm{BL}, \mathrm{HCH}$ and $\mathrm{CCH}$ configurations. Similar to the specific 


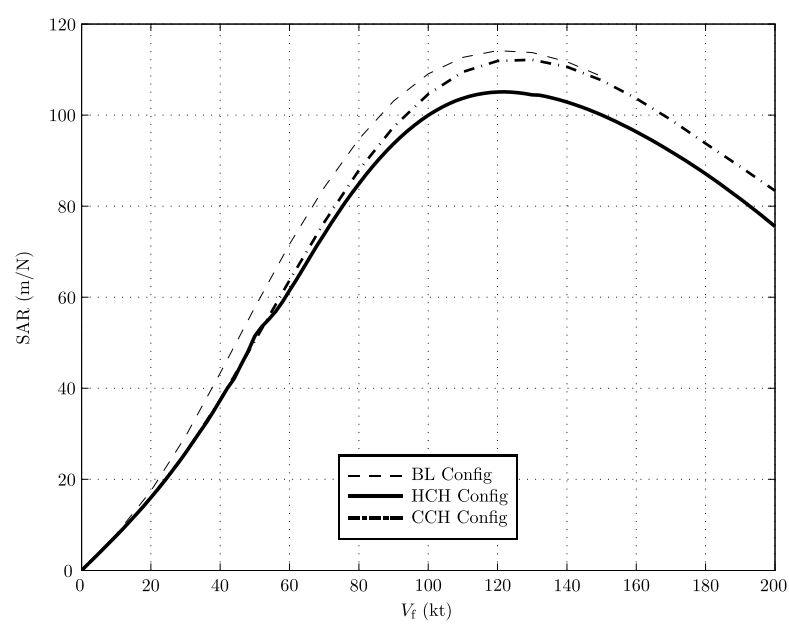

(a) Specific Range

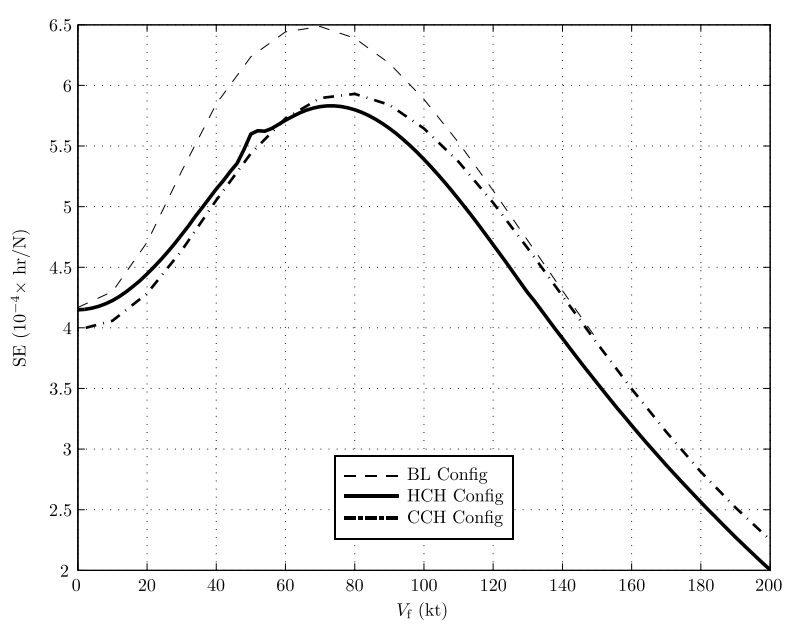

(b) Specific Endurance

Fig. 5. Predicted Specific Range and Endurance of the Three Aircraft Configurations at MSL

air range, the endurance can be determined by the product of the specific endurance and weight of the aircraft fuel. The maximum endurance of each of the configurations is achieved when their respective power is at its lowest, which can be determined from Figures 2 and 3. Consequently, the BL configuration achieves the lowest power setting of the three configurations at $67 \mathrm{kt}$, whereas the best endurance speeds of the $\mathrm{HCH}$ and $\mathrm{CCH}$ configurations are 74 and 82 , respectively. It is interesting to note that despite the addition of compounding to both compound helicopters, the shape of the SE curve is similar to that of a conventional helicopter. Comparing the BL configuration to the two compound helicopters, the estimated endurance of the $\mathrm{BL}$ configuration is greater due to lower power requirements predicted in Figure 2. At this speed, between $60-80 \mathrm{kt}$, the combination of the BL configuration's main rotor providing both the lifting and propulsive forces as well as the fin offloading the tail rotor allows the vehicle to achieve a lower power setting than the two compound helicopters. The maximum endurance of the two compound configurations are similar, although the endurance of the $\mathrm{CCH}$ configuration is slightly higher, which is consistent Figure 4. Within this speed range the addition of thrust compounding is not particularly beneficial, as the propeller(s) require power but not much propulsive force is needed.

\section{Mission Analysis}

The performance of a helicopter flying a given mission is of profound interest to the operator of the aircraft. The helicopter is designed to be capable of performing various missions such as anti-tank, anti-submarine and search and rescue. Each mission is unique with some missions requiring the helicopter to hover for sustained periods of time whereas with other missions the helicopter operates at a high speed for a considerable time. The following analysis estimates the performance of the three aircraft configurations flying standard helicopter missions. The first mission is a standard mission, as shown in Figure 6, with the helicopter beginning at the runway and flying for some specified distance or time to reach its destination. 


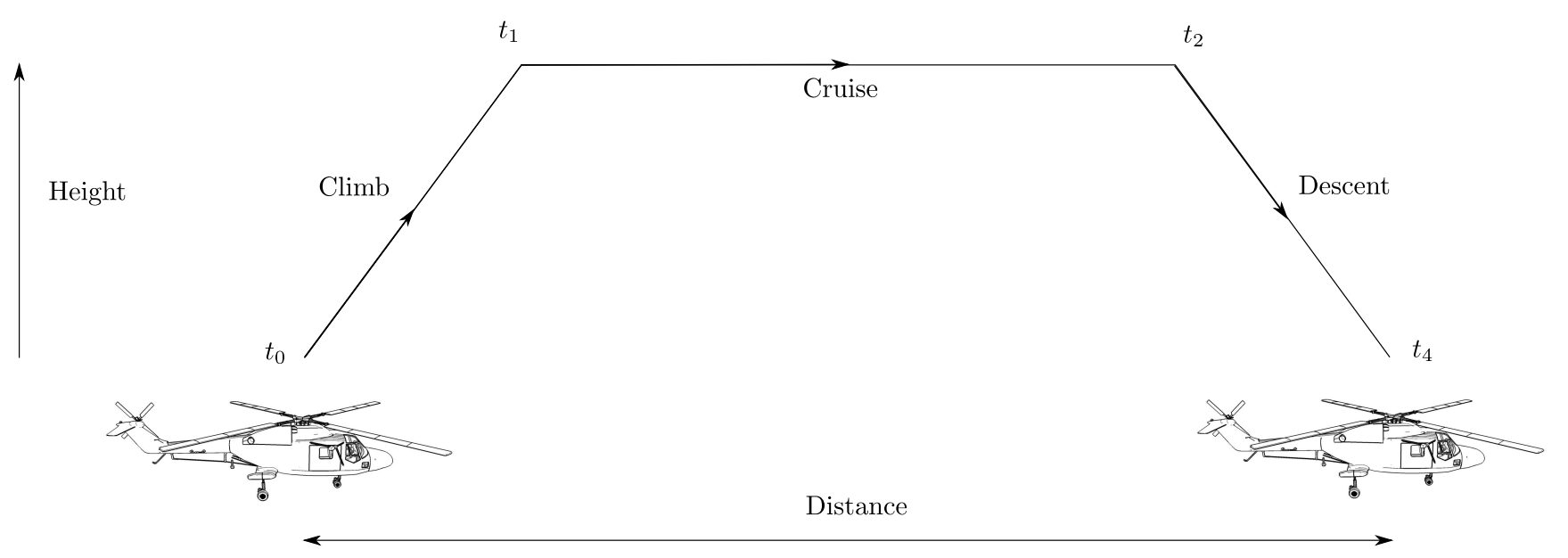

Fig. 6. Mission Profile Reproduced From References [2; 30]

\section{Loiter Mission}

The helicopter can successfully perform search and surveillance operations due to its unique ability to hover and land in demanding environments. For these particular types of missions the helicopter's crew search or patrol large areas whilst operating the aircraft at the lowest possible power setting to maximise endurance. Of course, maximising the endurance of the helicopter is of key interest to any operator so that the helicopter can successfully patrol an area for an extended period of time without the need to refuel.

The loiter mission is split into five main sections, namely, the start up, climb, cruise, descent and shut down portions. Each of these respective sections is discretised into small time increments, typically $25 \mathrm{~s}$, to take into account the fuel burn and its affect on the vehicle's mass which consequently alters the power requirements throughout the mission. An additional advantage of this approach is that the change of density due to altitude changes can modelled easily. The total length of the mission is two hours and it is assumed that the helicopter accelerates to its best endurance flight speed at the take-off site before climbing to the cruise altitude of $2 \mathrm{~km}$. In the loiter mission it is assumed that the flight speed does not vary throughout the mission. In the climb section of the mission, it is assumed that each of the aircraft configurations take 4 mins to reach their cruise altitude. This corresponds to the vehicles climbing at a glideslope angle of $\approx 10^{\circ}$, so that the configurations reach their specified altitudes in a timely manner without exceeding the power available. However, in the descent segment of the mission the glideslope is set to a constant value of $-3^{\circ}$ to avoid the respective main rotors reaching their autorotational conditions. Moreover, it is assumed that all of the three aircraft configurations operate at their maximum continuous power (MCP) settings for a small period of time at the start up and shut down segments, with five minutes being a typical time for these sections [45], to take into account the fuel burnt whilst performing procedural checks.

Table 4 shows the power and the fuel burnt throughout the loiter mission for the three helicopter types. The power of all three configurations rises in the climb portion of the mission, relative to their cruise power settings, as each configuration requires greater induced rotor power in order to climb to an altitude of $2 \mathrm{~km}$. The BL configuration 
operates at the lowest power setting of $438 \mathrm{~kW}$ in the cruise segment of the mission whereas the two compound configurations operate at comparable power settings. The power settings of the $\mathrm{HCH}$ and $\mathrm{CCH}$ configurations in the cruise portion are $516 \mathrm{~kW}$ and $524 \mathrm{~kW}$, respectively. This is consistent with Figure $5(\mathrm{~b})$ which predicts comparable endurance performance between the two compound helicopter configurations at mean sea level. As the vehicles operate at the cruise condition for the majority it follows that the $\mathrm{HCH}$ and $\mathrm{CCH}$ configurations burn a greater amount of fuel relative to the $\mathrm{BL}$ configuration. The $\mathrm{BL}$ configuration requires $334 \mathrm{~kg}$ of fuel to complete this mission whereas the two compound helicopter configurations burn approximately $10 \%$ more.

\begin{tabular}{|c|c|c|c|c|c|c|}
\hline \multirow[b]{2}{*}{ Mission Phase } & \multicolumn{2}{|c|}{$\begin{array}{c}\text { BL Config } \\
V_{\text {cruise }}=75 \mathrm{kt} \\
t=2 \mathrm{hr}\end{array}$} & \multicolumn{2}{|c|}{$\begin{array}{c}\mathrm{HCH} \text { Config } \\
V_{\text {cruise }}=81 \mathrm{kt} \\
t=2 \mathrm{hr}\end{array}$} & \multicolumn{2}{|c|}{$\begin{array}{c}\text { CCH Config } \\
V_{\text {cruise }}=87 \mathrm{kt} \\
t=2 \mathrm{hr}\end{array}$} \\
\hline & Power (kW) & Fuel Burnt (kg) & Power (kW) & Fuel Burnt (kg) & Power (kW) & Fuel Burnt (kg) \\
\hline Start up & 1300 & 27.27 & 1300 & 27.27 & 1300 & 27.27 \\
\hline Climb & 899 & 16.8 & 979 & 17.96 & 955 & 17.6 \\
\hline Cruise & 438 & 243.5 & 516 & 271.84 & 524 & 274.7 \\
\hline Descent & 277 & 18.9 & 356 & 21.3 & 370 & 21.7 \\
\hline Shut down & 1300 & 27.27 & 1300 & 27.27 & 1300 & 27.27 \\
\hline Total Fuel Burnt & & 333.74 & & 365.44 & & 368.24 \\
\hline
\end{tabular}

Table 4. Power and Fuel Burnt Throughout the Loiter Mission

\section{Range Mission}

Another typical mission that a helicopter performs is the so called range mission. This is a mission whereby the helicopter carries payload from a particular starting point to a destination, that is a specified distance away. If the distance is significant then a fixed wing aircraft would be commonly used to fulfil the mission whilst managing to carry a much greater payload than a helicopter. However, the helicopter's unique ability to operate safely at low speeds and land in demanding environments makes it suitable for various missions, such as ship replenishment. Furthermore, one of the perceived roles of the compound helicopter, due to its greater speed, is that it could perform flights in the civil market, i.e. city-hops. A light fixed wing aircraft would perform the mission quicker than that of a compound helicopter but this class of aircraft does has the additional advantage of being able to land in a populated city environment rather than an airport, which could subsequently reduce travel time.

The main aim of the loiter mission is to minimise fuel burn whereas the range mission is concerned with maximising the distance travelled for a given quantity of fuel [45]. The time of the range mission can be simply calculated by defining the climb, cruise and descent flight speeds and using the specified distance that the aircraft is to travel. Similar to that of the loiter mission, it is assumed that the aircraft begins at the take-off site at its climb speed before commencing its ascent to a cruise altitude of $2 \mathrm{~km}$. The aim of the range mission is to maximise the distance travelled per unit fuel, hence the cruise flight speed should correspond to the condition where the ratio $P_{\text {tot }} / V_{\mathrm{f}}$ is at a minimum. Whilst this is true, the SAR curve (Figure 5(a)), is relatively flat where the ratio $P_{\text {tot }} / V_{\mathrm{f}}$ is at a minimum. Hence, a greater flight speed can be chosen without adversely reducing the range of the aircraft [30; 35]. Therefore, 


\begin{tabular}{|c|c|c|c|c|c|c|}
\hline \multirow[b]{2}{*}{ Mission Phase } & \multicolumn{2}{|c|}{$\begin{array}{c}\text { BL Config } \\
V_{\text {cruise }}=140 \mathrm{kt} \\
t=1.65 \mathrm{hr}\end{array}$} & \multicolumn{2}{|c|}{$\begin{array}{c}\mathrm{HCH} \text { Config } \\
V_{\text {cruise }}=161 \mathrm{kt} \\
t=1.46 \mathrm{hr}\end{array}$} & \multicolumn{2}{|c|}{$\begin{array}{c}\text { CCH Config } \\
V_{\text {cruise }}=168 \mathrm{kt} \\
t=1.40 \mathrm{hr}\end{array}$} \\
\hline & Power (kW) & Fuel Burnt (kg) & Power (kW) & Fuel Burnt (kg) & Power (kW) & Fuel Burnt (kg) \\
\hline Start up & 1300 & 27.27 & 1300 & 27.27 & 1300 & 27.27 \\
\hline Climb & 899 & 16.8 & 979 & 17.96 & 955 & 17.6 \\
\hline Cruise & 724 & 278.5 & 1056 & 324.56 & 1052 & 308.8 \\
\hline Descent & 278 & 19.3 & 352 & 21.2 & 366 & 21.8 \\
\hline Shut down & 1300 & 27.27 & 1300 & 27.27 & 1300 & 27.27 \\
\hline Total Fuel Burnt & & 369.14 & & 418.26 & & 402.74 \\
\hline
\end{tabular}

Table 5. Power and Fuel Burnt Throughout the Range Mission

whilst in the cruise segment of the mission each of these aircraft configurations travel at their maximum operating speeds to reduce travel time. Generally, the time taken to complete the mission and the fuel burn are of equal importance to operators. However, in the climb stage of the mission the aircraft configurations operate at their minimum endurance speeds, where the maximum climb rate is achieved, so that they can ascent to the cruise altitude as quickly as possible.

Table 5 shows the predicted power and fuel burn of the $\mathrm{BL}, \mathrm{HCH}$ and $\mathrm{CCH}$ configurations performing a $400 \mathrm{~km}$ range mission. The three aircraft configurations reach the cruise altitude of $2 \mathrm{~km}$ in 4 mins which requires a significant amount of power for each configuration. In terms of the descent portion of the mission, the power of all three configurations reduce, relative to the power in cruise, as expected. During the cruise stage of the mission the conventional Lynx helicopter travels at its maximum operating speed of 140kt, which is stated in Ref [44], consequently requiring $369 \mathrm{~kg}$ of fuel to complete the mission. Although the $\mathrm{BL}$ configuration requires the least amount of fuel, it does take the longest time of $1.65 \mathrm{hr}$ to to complete the mission. One of the main perceived benefits of the compound helicopter is to operate at greater speeds than the conventional helicopter by avoiding the main rotor's inherent aerodynamic restrictions. Of course, this increase speed would reduce the time the vehicle would take to complete various missions and roles. The results presented here do capture this benefit with both the $\mathrm{HCH}$ and $\mathrm{CCH}$ configurations completing the mission in a shorter span of time relative to the $\mathrm{BL}$ configuration. The $\mathrm{CCH}$ configuration takes $1.40 \mathrm{hr}$ whereas the $\mathrm{HCH}$ configuration completes the mission in $1.46 \mathrm{hr}$. However, there is penalty with regards to the amount of fuel required. This is primarily due to the conventional helicopter operating at lower power setting of $724 \mathrm{~kW}$ in the cruise whereas the compound helicopter configurations require $\approx 45 \%$ more power at this stage. When comparing the compound helicopter configurations, the $\mathrm{CCH}$ configuration requires $15.5 \mathrm{~kg}$ less fuel than the $\mathrm{HCH}$ configuration. Although the power in the cruise of the two configurations is comparable, the higher cruise speed of $\mathrm{CCH}$ configuration results in less fuel being burnt.

\section{Conclusions}

This paper has examined the effect of compounding and its influence on the performance of compound helicopter configurations. The main conclusions of this study are listed: 
- The results confirm that the conventional helicopter's fuselage shape is not suitable for a high speed design and that a compound helicopter would require an optimised airframe design to reduce drag at high speed.

- As expected, the addition of wing compounding to the $\mathrm{HCH}$ configuration reduces the main rotor power at high speeds. However, the power of two propellers, which provide the thrust compounding, increase with air speed to produce the propulsive force to overcome the airframe drag. The net result is that the $\mathrm{HCH}$ configuration requires greater power than the $B L$ configuration across the speed range.

- Concerning the $\mathrm{CCH}$ configuration, the addition of thrust compounding does not significantly influence the performance of the vehicle below flight speeds of $100 \mathrm{kt}$ as the propeller is not required to produce axial thrust. Consequently, at this flight speeds it is the coaxial rotor that determines the performance of this vehicle. However, after $100 \mathrm{kt}$ the propeller provides a significant portion of axial thrust to divorce the coaxial rotor of its propulsive duties. The results predict that the $\mathrm{BL}$ configuration requires greater power than the $\mathrm{CCH}$ configuration between speeds of $100-150 \mathrm{kt}$.

- With the assumption that the three aircraft configurations are of the same vehicle shape and mass, the compound helicopter configurations show modest increases of maximum speed relative to the BL configuration. However, the maximum speeds of the compound configurations can be significantly increased by a combination of airframe drag reduction and increasing the installed engine power. Hence, as expected, the addition compounding can increase the maximum speeds of the vehicles if the design is further optimised.

- In terms of the hover ceilings of the three configurations, the BL configuration achieves the greatest hover ceiling whilst the $\mathrm{HCH}$ configuration achieves a lower hover ceiling due to the aerodynamic download of the wing. Regarding the $\mathrm{CCH}$ configuration, the level of modelling presented within predicts that it obtains a hover ceiling of $2529 \mathrm{~m}$. The addition of thrust compounding has a minor influence regarding this result as the propeller is pitched to provide a limited amount of thrust. Hence, it is the design of the coaxial rotor which determines the vehicle's hover ceiling. It is logical to assume that further optimisation of the design through nonlinear rotor blade twist would enhance the hover ceiling estimated in this study.

- The predicted maximum ranges of the $\mathrm{BL}$ and $\mathrm{CCH}$ configurations are similar. The estimated maximum range of the $\mathrm{HCH}$ configuration is $6 \%$ less than the $\mathrm{CCH}$ and $\mathrm{BL}$ configurations. However it is highlighted that the inclusion of wing compounding to the HCH configuration's design opens the possibility to store additional fuel provisions. In terms of the endurance results, the BL configurations is capable of the longest endurance. The predicted maximum endurance of the two compound helicopter configurations are similar. The maximum endurances occur at speeds between $70-80 \mathrm{kt}$, where the benefit of either thrust of wing compounding is not fully realised.

- Concerning the loiter mission, the BL configuration burns the least fuel of the three configurations. The BL configurations burns $334 \mathrm{~kg}$ of fuel whereas the $\mathrm{CCH}$ and $\mathrm{HCH}$ configurations burn approximately $366 \mathrm{~kg}$ of 
fuel. This result is consistent with the specific endurance results presented. With the range mission, the $\mathrm{CCH}$ configuration operates at the highest cruise speed, allowing the vehicle to complete the mission in $1.4 \mathrm{hr}$, which is quicker than both the $\mathrm{BL}$ and $\mathrm{HCH}$ configurations. The addition of thrust and wing compounding to the compound helicopters do indicate that significant reductions in mission time can be achieved. However, this must be balanced with the penalty of burning more fuel than a conventional helicopter of the same vehicle shape and size. In can be concluded, with some confidence, that with further optimisation of the compound helicopter design further gains can be made in terms of flight time reduction whilst minimising the fuel burn.

\section{Acknowledgements}

The authors would like to acknowledge the Scottish Funding Council (SFC) for providing the funding, under the GRPE Scholarship, to conduct this research.

\section{References}

[1] Orchard, M. and Newman, S., "The compound helicopter - why have we not succeeded before?" The Aeronautical Journal, Vol. 103, (1028), 1999, pp. 489-495.

[2] Leishman, J., Principals of Helicopter Aerodynamics, Cambridge University Press, second edition, 2006.

[3] Burgess, R., "The ABC Rotor - A Historical Perspective," American Helicopter Society 60th Annual Forum, 2004.

[4] Bagai, A., "Aerodynamic Design of the X2 Technology Demonstrator Main Rotor Blade," American Helicopter Society 64th Annual Forum, 2008.

[5] Blackwell, R. and Millott, T., "Dynamics Design Characteristics of the Sikorsky X2 Technology Demonstrator Aircraft," American Helicopter Society 64th Annual Forum, 2008.

[6] Walsh, D., Weiner, S., Bagai, A., Lawerence, T., and Blackwell, R., "Development Testing of the Sikorsky X2 Technology Demonstrator," American Helicopter Society 65th Annual Forum, 2009.

[7] Johnson, W., "Influence of Lift Offset on Rotorcraft Performance," AHS Specialist's Conference on Aeromechanics, 2008.

[8] Johnson, W., "Rotorcraft Aeromechanics Applications of a Comprehensive Analysis," HeliJapan 1998: AHS International Meeting on Rotorcraft Technology and Disaster Relief, 1998.

[9] Yeo, H. and Johnson, W., "Investigation of Maximum Blade Loading Capability of Lift-Offset Rotors," Journal of the American Helicopter Society, Vol. 59, (1), 2014, pp. 1-12.

doi: 10.4050/JAHS.59.012005 
[10] Sekula, M. and Gandhi, F., "Effects of Auxiliary Lift and Propulsion on Helicopter Vibration Reduction and Trim," AlAA Journal of Aircraft, Vol. 41, (3), 2004, pp. 645-656.

doi: $10.2514 / 1.496$

[11] Prouty, R., Helicopter Performance, Stability, and Control, Robert E. Krieger Publishing Company, Inc., reprint edition, 1990.

[12] Orchard, M. and Newman, S., "Some design issues for the optimisation of the compound helicopter configuration," American Helicopter Society 56th Annual Forum, 2000.

[13] M.Buhler and Newman, S., "The Aerodynamics of the Compound Helicopter Configuration," The Aeronautical Journal, Vol. 100, (994), 1996, pp. 111-120.

[14] Yeo, H. and Johnson, W., "Optimum Design of a Compound Helicopter," AIAA Journal of Aircraft, Vol. 46, (4), 2009.

doi: 10.2514/1.40101

[15] Moodie, A. and Yeo, H., "Design of a Cruise-Efficient Compound Helicopter," Journal of the American Helicopter Society, Vol. 57, (3), 2012.

doi: 10.4050/JAHS.57.032004

[16] Filippone, A., Flight Performance of Fixed and Rotary Wing Aircraft, Elsevier Ltd., first edition, 2006.

[17] Padfield, G., Helicopter Flight Dynamics: the Theory and Application of Flying Qualities and Simulation Modelling, Blackwell Publishing, second edition, 2007.

[18] Thomson, D., "Development of a Generic Helicopter Mathematical Model for Application to Inverse Simulation," Internal Report No. 9216, Department of Aerospace Engineering, University of Glasgow, UK, 1992.

[19] Ferguson, K. and Thomson, D., "Flight dynamics investigation of compound helicopter configurations," $A I A A$ Journal of Aircraft, Vol. AIAA Early, 2014.

doi: $10.2514 / 1 . C 032657$

[20] Thomson, D. and Bradley, R., "Inverse simulation as a tool for flight dynamics research - Principles and applications," Progress in Aerospace Sciences, Vol. 42, (3), May 2006, pp. 174-210.

doi: 10.1016/j.paerosci.2006.07.002

[21] Bramwell, A., Helicopter Dynamics, Edward Arnold, first edition, 1976, p. 212.

[22] Kim, F., Celi, R., and Tischler, M., "Forward flight trim and frequency response validation of a helicopter simulation model," AIAA Journal of Aircraft, Vol. 30, (6), 1993, pp. 854-863.

doi: $10.2514 / 3.46427$ 
[23] Rutherford, S., Simulation Techniques for the Study of Advanced Rotorcraft, Phd, University of Glasgow, 1997.

[24] Mansur, M., "Development and Validation of a Blade Element Mathematical Model for the AH-64A Apache Helicopter," NASA-TM-108863, 1995.

[25] Houston, S., "Rotorcraft Aeromechanics Simulation for Control Analysis - Mathematical Model Definition," Internal Report No. 9123, Department of Aerospace Engineering, University of Glasgow, UK, 1991.

[26] Doyle, S. and Thomson, D., "Modification of a helicopter inverse simulation to include an enhanced rotor model," AIAA Journal of Aircraft, Vol. 37, (3), 2000, pp. 536 - 538.

doi: $10.2514 / 2.2633$

[27] Bradley, R., Padfield, G., Murray-Smith, D., and Thomson, D., "Validation of helicopter mathematical models," Transactions of the Institute of Measurement and Control, Vol. 12, (186), 1990.

doi: $10.1177 / 014233129001200405$

[28] Anderson, J., Fundamentals of Aerodynamics, McGraw-Hill Book Company, fourth edition, 2007.

[29] Ballin, M., "Valiation of a real-time engineering simulation of the UH-60A helicopter," NASA TM-88360, 1987.

[30] Keys, C., "Performance Prediction of Helicopters," Rotor-Wing Aerodynamics, edited by W. Stepniewski, Dover Publications, Inc., 1981.

[31] Cooke, A. and Fitzpatrick, E., Helicopter Test and Evaluation, Blackwell Science, Oxford, U.K., 2002.

[32] Yeo, H., "Investigation of UH-60A Rotor Performance and Loads at High Advance Ratios," Journal of Aircraft, Vol. 50, (2), 2013, pp. 576-589.

doi: $10.2514 / 1 . C 031958$

[33] Ormiston, R., "Low-Disk Loading Compound Rotorcraft for High-Speed and Aerodynamic Efficiency," International Powered Lift Conference 2010, 2010.

[34] Ruddell, A., "Advancing Blade Concept (ABC) Development," American Helicopter Society 32nd Annual Forum, 1976.

[35] Johnson, W., Rotorcraft Aeromechanics, Cambridge University Press, 2013, p. 243.

[36] Allan, B. and Schaeffler, N., "Numerical Investigation of Rotorcraft Fuselage Drag Reduction using Active Flow Control," American Helicopter Society 67th Annual Forum, 2011.

[37] Jordan, T., Humpherson, D., and Benger, B., "The compound helicopter - The rotorcraft for the 21st Century?" American Helicopter Society 49th Annual Forum, 1993. 
[38] Kim, H. and Brown, R., "A Rational Approach to Comparing the Performance of Coaxial and Conventional Rotors," Journal of the American Helicopter Society, Vol. 55, (1), 2010, pp. 012003.

doi: 10.4050/JAHS/55.012003

[39] Kim, H. and Brown, R., "A Comparison of Coaxial and Conventional Rotor Performance," Journal of the American Helicopter Society, Vol. 55, (1), 2010, pp. 012004.

doi: 10.4050/JAHS.55.01.2004

[40] Harrington, R., "Full-Scale-Tunnel Investigation of the Static-Thrust Performance of a Coaxial Helicopter Rotor," NACA TN-2318, 1951.

[41] Dingeldein, R., "Wind-Tunnel Studies of the Performance of Multirotor Configurations," NACA TN 3236, 1954.

[42] Arents, D., "An Assessment of the Hover Performance of the XH-59A Advancing Blade Concept Demonstration Helicopter," USAAMRDL-TN-25, 1977.

[43] Williams, R. and Montana, P., "A Comprehensive Plan for Helicopter Drag Reduction," American Helicopter Society Symposium on Helicopter Aerodynamic Efficiency, 1975.

[44] Anon., Jane's All the World's Aircraft, Jane's Information Group, 85th edition, 1994.

[45] Keys, C., "Performance Prediction of Helicopters," Rotary-wing Aerodynamics, edited by W. Stepniewski, Chap. Volume II, 1979.

[46] Felker, F. and Light, J., "Aerodynamics Interactions Between a Rotor and Wing in Hover," American Helicopter Society 42th Annual Forum, 1986.

[47] Leishman, J. and Ananthan, S., "An Optimum Coaxial Rotor System for Axial Flight," Journal of the American Helicopter Society, Vol. 53, (4), 2008, pp. 366-381.

doi: 10.4050/JAHS.53.366

[48] Johnson, W., Helicopter Theory, Dover Publications, Inc., second edition, 1994.

[49] Sanderson, A., "Projected Power and Specific Fuel Consumption Development of the Rolls Royce Gem Engine," American Helicopter Society 37th Annual Forum, 1981. 